\title{
Deep-sea discoveries
}

\author{
The sea floor is emerging as a source of carbon to the overlying ocean. Scientific exploration of the sea \\ bed is essential for a full understanding of the global carbon budget and the safety of deep-sea carbon \\ storage proposals.
}

Carbon bound up in seafloor sediments is thought to have played a key role in past episodes of climate change. The break-up of the northeast Atlantic continents around 55 million years ago was associated with the injection of large amounts of molten magma into carbon-rich sediments on the sea floor. The heating of these sediments may have triggered the release of large quantities of methane and carbon dioxide into the overlying ocean and atmosphere (Nature 429, 542-545; 2004). The thermogenic alteration of these sediments, and the subsequent release of methane, has been suggested to be one of the factors responsible for the onset of the PalaeoceneEocene Thermal Maximum, the prolonged period of warming lasting over 100,000 years (Nature Geosci. 2, 156-159; 2009).

Despite the potential importance of seafloor carbon sources in shaping past climate, little is know about their involvement in the present day carbon cycle. Three Letters published in this issue (on pages 50, 32 and 37) suggest that carbon trapped beneath the sea bed continues to influence carbon dynamics, at least in the deep ocean.

Seafloor spreading centres - where two or more oceanic plates pull apart are hotbeds of magmatic activity, owing to the eruption of molten magma from below. Hydrothermal vents are common at these spreading sites. These vents emit large quantities of geothermally heated, mineral-rich fluids. The minerals and energy contained in these fluids support a huge diversity of microbes and invertebrates, such as giant tube worms and clams, in an otherwise barren sea floor.

Magmatic activity in one such spreading centre seems to be triggering methane release (see Letter on page 50 and News \& Views on page 11 ). In the geologically young Guaymas basin in the Gulf of California, magma has intruded into vast areas of the thick, organic sediments at the bottom of the basin. The heating of these sediments - that had been thought to sequester rather than emit carbon - seems to have resulted in the release of methane into the overlying ocean.

Further north at the Juan de Fuca Ridge, in the Northeast Pacific Ocean, another form of carbon is emanating from the sea floor in an older and more-developed seafloor spreading centre (see Letter on page 32 ). Here, isotopic analyses suggest that microbes in the hydrothermal fluids that circulate through the ocean crust convert ancient inorganic carbon into dissolved organic matter, which is subsequently vented to the overlying ocean. Previously, most of the dissolved organic carbon at the bottom of the ocean was thought to originate from carbon captured by photosynthetic organisms in the upper ocean (see News \& Views on page 9), and not from the sea floor.

And in an entirely different oceanbottom setting off the west coast of Canada, gas hydrates - ice-like mixtures of gases and water that are held in place by the specific temperature and pressure conditions on the shallow sea floor - also seem to be serving as a source of dissolved organic carbon to the overlying ocean (see Letter on page 37).

The ultimate impact of the carbon emitted from these emerging and distinct seafloor sources, and its contribution to the global carbon budget, is uncertain. At this stage we do not know whether similar processes operate at other hydrothermal and gas hydrate systems, how much carbon is being emitted, or, in the case of the dissolved organic carbon released from Juan de Fuca Ridge and the hydrates, how reactive the released carbon is. To find out more, further exploration of the sea floor will be essential. Ocean drilling will be a key component of these investigations (see Commentary on page 3 ).

Of course, the present focus on carbon research is motivated by the need to understand how anthropogenic carbon dioxide emissions will affect the Earth system. To mitigate such effects, the sea floor - where natural sources of carbon are just being discovered - has been proposed as a potential site for carbon sequestration (Nature Geosci. 2, 815-818; 2009; Nature Geosci. 2, 820-822; 2009). As long as the natural carbon cycle in the deep ocean continues to surprise us, it would probably be unwise to go ahead and disturb it with the deposition of carbon captured from the use of fossil fuels.

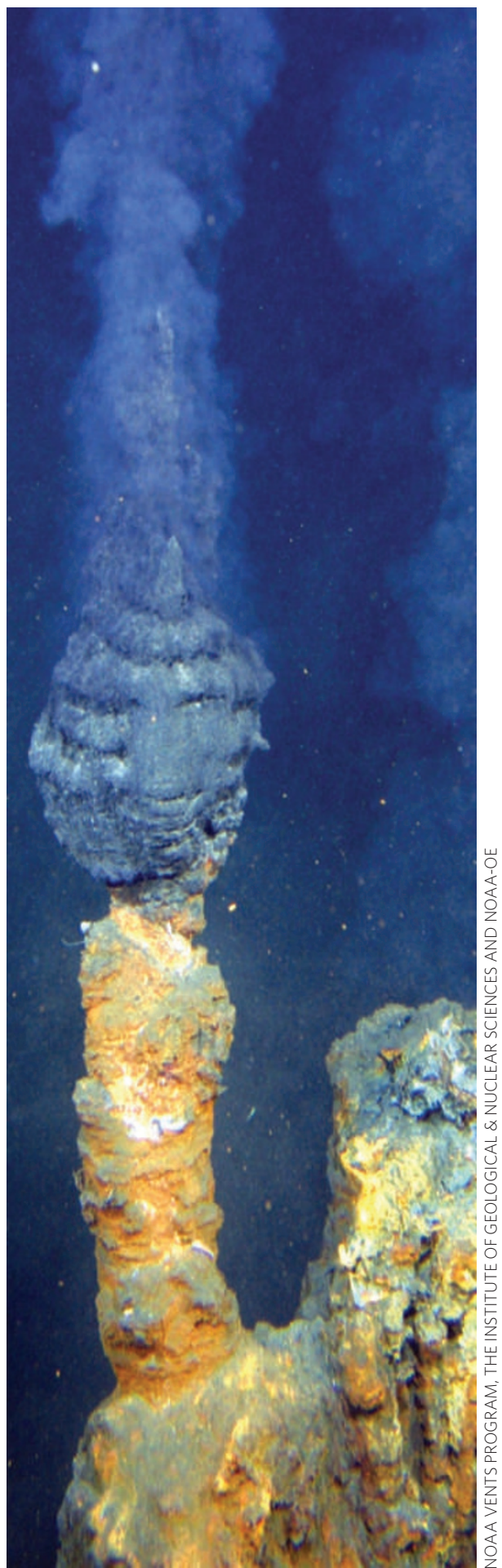

